\title{
Bio-social origins of depression in the community
}

\author{
Interactions between social adversity, cortisol \\ and serotonin neurotransmission ${ }^{\dagger}$ \\ PAUL L. STRICKLAND, J. F. WILLIAM DEAKIN, CAROL PERCIVAL, \\ JOANNE DIXON, RICHARD A. GATER and DAVID P. GOLDBERG
}

\begin{abstract}
Background Social adversity may bea risk factor for depression, by increasing cortisol secretion, which impairs serotonin (5-HT) neurotransmission.
\end{abstract}

\begin{abstract}
Aims To examine this causal pathway in a community setting.
\end{abstract}

\begin{abstract}
Method Women who were currently ICD-10 depressed $(n=94)$, vulnerable to depression but not depressed $(n=166)$ and non-vulnerable controls $(n=177)$ were recruited.We assessed social adversity and vulnerability (Life Events and Difficulties Schedule; Self Evaluation and Social Support Scales) and psychiatric state (Schedules for Clinical Assessment in Neuropsychiatry). Salivary cortisol concentrations were measured at 09.00 and $23.00 \mathrm{~h}$. Serotonin function was assessed using prolactin responses to dexfenfluramine.
\end{abstract}

Results Cortisol concentrations were not increased in the depressed or vulnerable. Morning salivary and serum cortisol were reduced in depression. Evening cortisol was increased after recent life events. Life events and depression were associated with increased prolactin responses.

\section{Conclusions The hypothalamic- pituitary-adrenal axis is sensitive to social stress but does not mediate vulnerability to depression. Exaggerated 5- $\mathrm{HT}_{2}$ receptor responsiveness to stress may play a role in the evolution of depression.}

\section{Declaration of interest Wellcome Trust funding.}

†See editorial, pp. 99-100, this issue.
It is established that psychosocial stress precedes the onset of depression (Brown \& Harris, 1989; Bifulco et al, 1998) but the intervening biological mechanisms are not understood. Increased cortisol secretion has been reported widely in depression and is believed to originate from psychosocial stress that induces changes in the brain underlying depression (Dinan, 1994; Nemeroff, 1996). In humans, two small studies reported increased cortisol in subjects with current depression whose illness was preceded by social stress (Dolan $e t$ al, 1985; Deakin et al, 1990), but there is scant evidence that hypercortisolaemia occurs in depression in community settings. The present study therefore was carried out in the community under naturalistic conditions. Studies have reported blunting of responses following administration of various serotonin (5-hydroxytryptamine, 5-HT) agonist drugs (Deakin et al, 1990; Mitchell \& Smythe, 1990; O’Keane \& Dinan, 1991). Some studies have reported that impaired 5-HT function is associated with increased baseline cortisol concentrations (Deakin et al, 1990; Mitchell \& Smythe, 1990). This has contributed to the widespread view that stress-induced increases in cortisol secretion cause depression by undermining 5-HT neurotransmission through glucocorticoid-5-HT interactions in the brain (Dinan, 1994). We investigated each step of this hypothetical causal sequence in a large community-based study and we tested the prediction that $5-\mathrm{HT}$ function would be reduced in subjects with current depression but not in subjects who were vulnerable but not yet depressed. In contrast, increased salivary cortisol would occur in both groups.

\section{METHOD}

\section{Screening and recruitment}

We aimed to recruit three groups of women: 100 women currently depressed by ICD-10
(World Health Organization, 1993) criteria; 300 women vulnerable to depression but not currently depressed; and 100 women not vulnerable to depression and not depressed. Group sizes to detect a cross-sectional group comparison on salivary cortisol were determined by power calculations using data from the large study by Stokes et al (1984). Women with children under the age of 16 years living in a south Manchester housing estate were identified from family doctor lists and sent screening questionnaires to assess current mood state (Personal Health Questionnaire, PHQ; Simpson, 1984) and vulnerability to depression (Health and Relationships Questionnaire, HRQ, adapted from the Vulnerability to Depression Questionnaire; Brown \& Harris, 1989).

\section{Interviews and assessments}

The women were interviewed twice in their homes. A psychiatrist (P.L.S.) conducted the first interview. The subjects were given a complete description of the study, written informed consent was obtained, demographic details were collected and a Schedules for Clinical Assessment in Neuropsychiatry (SCAN) diagnostic interview (World Health Organization, 1992) was conducted. Four tubes were left for saliva collection over two days at 09.00 and $23.00 \mathrm{~h}$ during the follicular phase of the menstrual cycle (day $0-12$ ) or on pill-free days for women taking the oral contraceptive pill.

At the second interview, within 2 weeks of the first, the Life Events and Difficulties Schedule (LEDS; Brown \& Harris, 1989) for the previous 6 months and the Self Evaluation and Social Support Scales (SESS; Brown et al, 1990) were administered by social researchers (C.P., J.D.). These interviews were used to determine vulnerability to depression and current depression.

\section{Serotonin neurotransmission}

Serotonin function was assessed by measuring prolactin responses to dexfenfluramine challenge in subgroups (20 depressed, 63 vulnerable and 61 non-vulnerable) during the follicular phase of the menstrual cycle (days 0-12 of cycle, similar test-timing for all groups) or during the contraceptivepill-free days. The subjects were drug-free and fasted from $23.00 \mathrm{~h}$. Dexfenfluramine (30 mg, oral) and placebo tests were separated by at least 2 days and the order was randomised and double blind. Baseline blood samples were taken an hour before $(09.30 \mathrm{~h})$ and at the time of drug/placebo 
administration $(10.30 \mathrm{~h})$. Hourly samples were taken thereafter. Baseline assays were $l$-tryptophan, branched-chain amino acids, cortisol and prolactin. Prolactin, fenfluramine and norfenfluramine were assayed in subsequent samples.

\section{Assays}

Salivary cortisol was measured by competitive radioimmunoassay (Kane, 1979). Inter-assay precision was $<13 \%$ at all levels. Intra-assay precision was $<6 \%$ across the whole assay range. Plasma-free tryptophan, branched-chain amino acids, fenfluramine and norfenfluramine concentrations were determined by a fluorimetric method (Franklin et al, 1995).

\section{Social adversity}

Life events were categorised into severe and non-severe and into recent (within the past month) and non-recent (>1 month, <6 months) using LEDS criteria.

\section{Vulnerability and depression}

Vulnerability was defined according to Brown et al (1990) as the presence of two or more vulnerability factors, at least one being environmental. Environmental factors are negative evaluation of core relationship (partner or child), social isolation and chronic difficulty. Psychological factors are low self-esteem, subclinical depression and parental separation for more than 1 year before the age of 16 years. Women assessed as being vulnerable to depression have a $25-30 \%$ risk of having a new onset of depression in the following year (Brown et al, 1990). Depression was defined using ICD-10 criteria (World Health Organization, 1993): depressive episode F32.0-32.2 or recurrent depressive disorder F33.033.2. Subsidiary analyses used DSM-IV criteria (American Psychiatric Association, 1994): major depression without psychotic symptoms 296.2-296.3.

\section{Statistical analysis}

Average morning and evening salivary cortisol and diurnal change were analysed. Cortisol concentrations at $23.00 \mathrm{~h}$ were not normally distributed and vulnerability and life event groups were compared using $\chi^{2}$ and Mann-Whitney $U$ tests. Wilcoxon paired rank tests were used for withinsubject comparisons.

Dexfenfluramine challenge was assessed using analysis of covariance of all prolactin data, with a repeated measures factor for sample time and factors for drug/placebo and vulnerability group, and using area under the prolactin curve (AUC) on the fenfluramine day minus AUC on the placebo day (placebo-controlled AUC, PC-AUC). The PC-AUC was normally distributed and therefore analysed by analysis of covariance. The following potential covariates were measured: AUC of fenfluramine and norfenfluramine concentrations; serum cortisol, tryptophan and branched-chain amino acid concentrations; the ratio of tryptophan to branched-chain amino acids; and weight change over the past month (categories were: none; $<2 \mathrm{~kg}$; a loss of $>2 \mathrm{~kg}$; a gain of $>2 \mathrm{~kg}$ ). The Statistical Package for the Social Sciences, version 7.5 (SPSS, 1997) was used.

\section{RESULTS}

\section{Sample characteristics}

A total of 5558 women were sent questionnaires. Using one reminder, $2112(38 \%)$ responded. Those likely to fall into the depressed, vulnerable or non-vulnerable groups were contacted until each cell was filled. A total of 755 women agreed to participate further in the study. Completed data were collected on 453 women (Table 1 ). It was not possible to recruit sufficient vulnerable women because often they were currently depressed, hence this cell was below target size and the non-vulnerable target was exceeded. A total of 94 women met the ICD-10 criteria for depression: 48 had mild depression, 37 had moderate depression and 9 had severe depression (as defined by ICD-10); $14.4 \%$ of the depressed group were taking antidepressants and
$7.2 \%$ were taking benzodiazepines. Eleven women were excluded due to current steroid treatment, physical illness or psychosis. All data from women recruited into the study have been included in the analysis.

\section{Cortisol concentrations}

Salivary cortisol concentrations showed diurnal variation (Table 2 and Fig. 1a). Although separated by several weeks, morning cortisol concentrations from the salivary and fenfluramine studies were correlated significantly $(r=0.31, n=160$, $P<0.001$ ).

Subjects meeting the criteria for ICD10 depression did not have increased salivary cortisol concentrations either in the evening or morning (Fig. 1a and Table 2). Indeed, there were reductions in the $09.00 \mathrm{~h}$ salivary cortisol and diurnal change in the depressed subjects of borderline statistical significance by two-tailed tests (Table 2). Similarly, average morning serum cortisol (from those who had dexfenfluramine tests) was reduced in depressed subjects (mean $=319.9$ and s.e. $=125.7 \mathrm{nmol} / \mathrm{l}, n=24)$ compared with non-depressed subjects (mean $=403.2$ and s.e. $=190.4 \mathrm{nmol} / \mathrm{l}, n=135, P=0.04$, oneway analysis of variance).

Severe recent life events were associated with increased $23.00 \mathrm{~h}$ salivary cortisol concentrations (Fig. $1 \mathrm{~b} ; P<0.002, \chi^{2}$ test), whereas recent non-severe events and severe events occurring more than a month previously were not. This association between life events and high evening salivary cortisol concentration remained unchanged when depressed patients were excluded. The association with life events was no more (or less) apparent in the depressed group.

Table I Numbers of subjects with social and biological data by diagnosis; an additional I5 subjects received active fenfluramine but not placebo

\begin{tabular}{|c|c|c|c|c|c|c|}
\hline & \multicolumn{2}{|c|}{ Salivary cortisol } & \multicolumn{2}{|c|}{ LEDS/SESS } & \multirow{2}{*}{\multicolumn{2}{|c|}{$\begin{array}{c}\text { Complete fenfluramine } \\
\text { challenge }\end{array}$}} \\
\hline & \multirow{2}{*}{ ICD-10 } & \multirow{2}{*}{ DSM-IV } & \multirow{2}{*}{ ICD-10 } & \multirow{2}{*}{ DSM-IV } & & \\
\hline & & & & & ICD-I0 & DSM-IV \\
\hline Non-vulnerable & 177 & 178 & 190 & 192 & 61 & 59 \\
\hline Vulnerable & 166 & 174 & 163 & 170 & 63 & 60 \\
\hline Depression & 94 & 48 & 95 & 49 & 20 & 8 \\
\hline Other diagnoses & 15 & 53 & 15 & 52 & I & 18 \\
\hline Total & 452 & 453 & 463 & 463 & 145 & 145 \\
\hline
\end{tabular}

LEDS, Life Events and Difficulties Schedule; SESS, Self Evaluation and Social Support Scales. 
Table 2 Salivary cortisol (nmol/l; $23.00 \mathrm{~h}, 09.00 \mathrm{~h}$ and diurnal) in each study group

\begin{tabular}{lcccc}
\hline & $\begin{array}{c}\text { Non-vulnerable } \\
(n=177)\end{array}$ & $\begin{array}{c}\text { Vulnerable } \\
(n=166)\end{array}$ & $\begin{array}{c}\text { ICD-10 depressed } \\
(n=94)\end{array}$ & $\begin{array}{c}\text { DSM-IV depressed } \\
(n=48)\end{array}$ \\
\hline $23.00 \mathrm{~h}$ & & & & \\
Mean & 2.37 & 2.14 & 2.47 & 2.54 \\
Median & 1.5 & 1.5 & 1.5 & 1.5 \\
Interquartile range & 1.5 & 1.0 & 1.13 & 1.5 \\
$09.00 \mathrm{~h}$ & & & & \\
Mean' & 8.12 & 7.68 & $7.38^{2}$ & $7.11^{3}$ \\
Median & 7.5 & 6.75 & 6.50 & 6.25 \\
Interquartile range & 5.0 & 5.0 & 4.63 & 4.25 \\
Diurnal & & & & \\
Mean & 5.73 & 4.92 & $4.92^{4}$ & $4.57^{4}$ \\
Median & 5.0 & 5.0 & 4.5 & 4.0 \\
Interquartile range & 5.0 & 4.5 & 5.0 & 4.25 \\
\hline
\end{tabular}

I. The $09.00 \mathrm{~h}$ cortisol is greater than the $23.00 \mathrm{~h}$ cortisol in all groups; Wilcoxon signed rank test.

2. $P=0.09$ v. non-vulnerable; two-tailed $U$ test.

3. $P=0.07 v$. non-vulnerable; two-tailed $U$ test.

4. $P<0.06$ v. non-vulnerable and vulnerable groups; two-tailed $U$ test.
The vulnerable, non-depressed group showed no evidence of increased cortisol concentrations. Almost all the currently depressed women fulfilled LEDS/SESS vulnerability criteria, largely owing to psychosocial difficulties and poor relationships. In a subsidiary analysis we investigated whether the hypothalamic-pituitary-adrenal (HPA) axis becomes responsive to these vulnerability factors in depression. Although those with current depression as a group did not have greater cortisol concentration than controls, dividing the depressed group into high- and low-difficulty groups
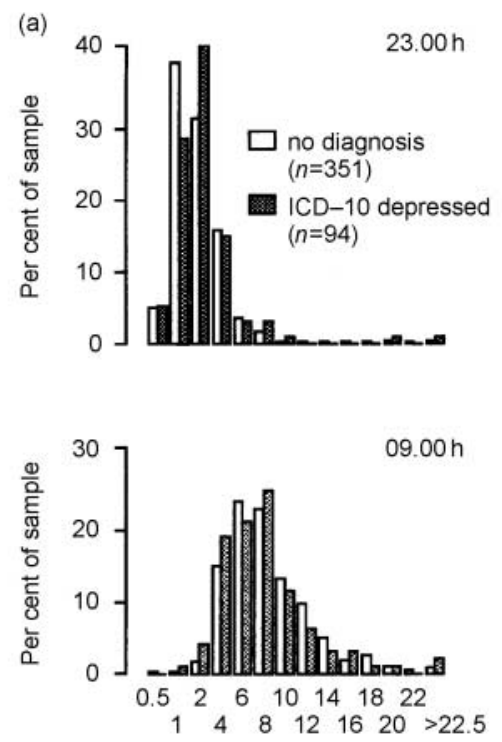

Salivary cortisol concentration (nmol/l)
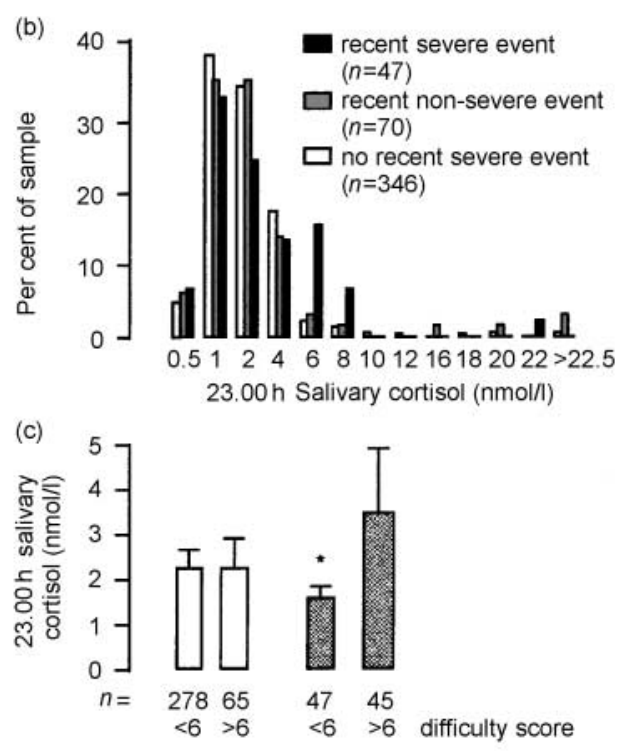

Not depressed Depressed

Fig. I Influence on salivary cortisol: (a) no increase in 9 a.m. or II p.m. salivary cortisol concentration in depressives; (b) severe recent life events are associated with increased II p.m. cortisol concentration $\left(P<0.002, \chi^{2}\right.$ test $)$; (c) chronic difficulties increase evening cortisol only in depressed subjects $(* P=0.01$ for high $v$. low difficulty score in the depressed; two-tailed Mann-Whitney $U$ test). by median difficulty score revealed that, in depression, chronic stress is associated with increased cortisol secretion (Fig. 1c). This was not seen in the non-depressed.

\section{Dexfenfluramine challenge tests}

Prolactin responses to dexfenfluramine were greater in depressed subjects than in vulnerable or non-vulnerable subjects by repeated-measures analysis (Fig. 2a; group $x$ drug $\times$ sample: $F=2.7 ; 12,846 ; P=0.002$ ) and by PC-AUC, with dexfenfluramine AUC and average $l$-tryptophan concentrations as covariates. Baseline cortisol and branched-chain amino acid concentrations were not significant covariates. Exploration of the effects of life events on 5-HT function was hampered by small subgroups, but fenfluramine responses were greater in the depressed with recent life events; in the absence of life events, prolactin responses tended to be reduced (Fig. 2b; life event $x$ group interaction: $F=5.7 ; 2,137 ; P=0.004$ ).

Tryptophan concentrations were reduced in those with recent severe life events compared with those with no recent severe events (Table 3). No reduction was found in other categories of life event severity or recency. Depression (ICD-10 or DSM-IV) was not associated with low tryptophan concentration. However, in the depressed subjects there were significant increases in branched-chain amino acid concentrations and this resulted in statistically significant reductions in the ratio of tryptophan to branched-chain amino acids (Table 3). None of the measures of tryptophan availability was a significant covariate in the analysis of covariance.

Self-rated weight loss did not influence the concentration of tryptophan or branched-chain amino acids. Fenfluramine responses were greater in the subgroup reporting mild degrees of weight loss $(<2 \mathrm{~kg}$ ) compared with the no-weight-loss group and the other groups; however, those with more severe degrees of weight loss and those with weight gain had entirely normal responses (data not shown).

\section{DISCUSSION}

The major findings of this study run counter to prevailing views: depression in the community is not associated with increased cortisol concentration and is associated with increased rather than decreased 5-HT responsivity. 

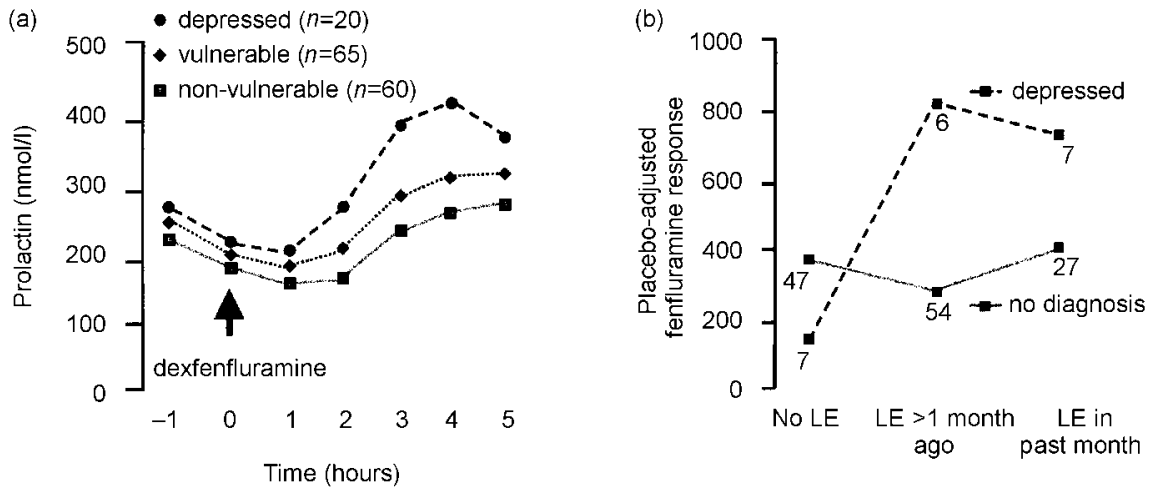

Fig. 2 Serotonin function as assessed by dexfenfluramine challenge test. (a) Prolactin response to dexfenfluramine is enhanced in depressed subjects (sample $\times$ drug $\times$ diagnostic group, $P=0.005$ ). (b) Placeboadjusted fenfluramine responses by life events (LE) and depression: main effect of depression, $P=0.03$; main effect of life event, $P=0.0$; life event $\times$ depression interaction, $P=0.004$.

Table 3 Tryptophan, branched-chain amino acids and tryptophan:branched-chain amino acid ratio by vulnerability and by recency of life events

Non-vulnerable $(n=64) \quad$ Vulnerable $(n=71) \quad$ Depressed $(n=24)$

\begin{tabular}{lccc}
\hline Tryptophan & & & \\
Mean & 9.16 & 9.15 & 8.60 \\
s.e. & 0.21 & 0.27 & 0.44 \\
Amino acids & & & \\
Mean' & 325.4 & 327.1 & $371.2^{*}$ \\
s.e. & 10.1 & 10.8 & 15.5 \\
Ratio $\times 10^{3}$ & & & \\
Mean & 30.0 & 30.0 & $23.9 * *$ \\
s.e. & 1.29 & 1.31 & 1.48 \\
\hline
\end{tabular}

No life events $(n=55) \quad$ Non-recent $(n=68) \quad$ Recent $(n=37)$

\begin{tabular}{llll}
\hline Tryptophan $^{2}$ & & & \\
Mean & 9.46 & 9.22 & $8.30^{*}$ \\
s.e. & 0.25 & 0.25 & 0.36 \\
\hline
\end{tabular}

I. $P<0.06$ for main effects; one-way analysis of variance.

2 . $P \leqslant 0.03$ for main effects; one-way analysis of variance.

*Post hoc least-squares method $P \leqslant 0.03 v$. vulnerable and non-vulnerable groups; $* * P<0.01$.

\section{Hypothalamic-pituitary-adrenal axis function and depression}

Increased secretion of cortisol in depression is widely held to be central to the pathogenesis of symptoms and to be caused by psychosocial stress (Stokes et al, 1984; Dinan, 1994; Nemeroff, 1996). This hypothesis has been difficult to reconcile with the low prevalence of hypercortisolaemia in milder depressive illnesses in which social stress plays an important aetiological role. In our study, cortisol was responsive to recent psychosocial stress but was not raised in depression. The majority of the cases of depression were of mild severity, but even in more severe cases and those fulfilling DSM-IV criteria ( $n=48$; Table 1$)$ there was no trend for increased cortisol concentrations. Indeed, we found evidence that morning cortisol in serum was reduced in depressed subjects and the same trend was seen in salivary cortisol. Reduced $09.00 \mathrm{~h}$ salivary cortisol has been reported in chronic fatigue syndrome (Strickland et $a l, 1998)$, in some studies of post-traumatic stress disorder and after traumatic events (Yehuda et al, 1995). These disorders are associated with anxiety and in the present study the currently depressed subjects with comorbid anxiety diagnoses had lower morning serum cortisol concentrations (data not shown).

\section{Hypothalamic-pituitary-adrenal axis function and psychosocial stress}

In the present study high ratings of psychosocial difficulty were associated with increased evening cortisol concentration, but only in the depressed group (Fig. 1c). This raises the possibility that some cases of community depression may involve a primary dysregulation of the HPA axis, which results in exaggerated cortisol responses to persistent adversity. Further analysis may reveal whether the dysregulation arises from early life experiences or from constitutional factors, and whether there is some symptomatic or personality correlate. A primary dysregulation of the HPA axis may account for the many reports of increased cortisol in in-patients with current depression, with the stress of admission interacting with a sensitised HPA axis (Maes et al, 1994). Indeed, a number of studies suggest that admission is an important influence on the prevalence of HPA axis dysregulation in depression. Our results contrast with a community-based study that found increased evening salivary cortisol in children and adolescents during depression (Goodyer et al, 1996). The explanation may lie in differences in age, gender, social class and, possibly, severity of the two samples. Our finding that life events are associated with greater salivary cortisol concentrations was not reported in two communitybased high-risk studies, but both studies specifically excluded currently depressed individuals, who would have had high rates of life events, and they were smaller studies (Goodyear et al, 2000; Harris et al, 2000).

\section{Serotonin function in depression: dexfenfluramine challenge tests}

Unexpectedly, we found that prolactin responses to dexfenfluramine were increased in the currently depressed individuals, especially those with recent life events, although the latter observation is based on small numbers. This result contrasts with three previous studies of psychiatric inpatients that have reported attenuated prolactin responses to $d / l$ - or $d$-fenfluramine (O’Keane \& Dinan, 1991; Lichtenberg et al, 1992; Siever et al, 1984). A further study reported decreased responses in an endogenous subgroup but the difference was 
not statistically significant when low baseline prolactin levels were covaried (Mitchell \& Smythe, 1990). Individuals with endogenous depression had smaller responses than patients with milder depression in one study (Lopez-Ibor et al, 1988) but in another the reverse was observed (Maes et $a l, 1989)$ and neither had healthy control groups. In a large study of primary care attenders with depression no change was found (Park et al, 1996). In these studies control groups have not been defined beyond matching on basic variables and by exclusion criteria. Our finding of increased prolactin responses is based on two exceptionally large control groups drawn from the same locality and socio-economic grouping as the depressed group, one of which also controlled for psychosocial vulnerability. Furthermore, the finding survives correction for all known influences on prolactin responses to fenfluramine: placebo challenge, baseline cortisol and prolactin, menstrual phase, drug and metabolite levels, tryptophan availability and weight loss.

One possible explanation for increased prolactin responses to dexfenfluramine is that weight loss and/or reduced tryptophan availability in the depressed group caused reduced 5-HT release and a secondary adaptive up-regulation of 5-HT receptor responsivity. This mechanism has been suggested for increased responses following dieting (Walsh et al, 1995; Cowen et al, 1996). In depressed patients, the ratio of tryptophan to branched-chain amino acids, which compete with each other for transport into the brain, was indeed reduced by $20 \%$ but this was not a significant covariate of responses. Furthermore, subjects with self-rated weight loss of $>2 \mathrm{~kg}$ showed no trend to increased dexfenfluramine responsiveness and there was no relationship between weight loss and measures of tryptophan availability. These considerations suggest that 5-HT receptor upregulation may not adequately explain the findings.

\section{Serotonin receptor subtypes: role of $5-\mathrm{HT}_{2}$ receptors in depression}

There is evidence that prolactin responses to dexfenfluramine are mediated through $5-\mathrm{HT}_{2 \mathrm{c}}$ receptors (Goodall et al, 1993). Thus, a more straightforward explanation for increased prolactin responses is that they are due to increased neurotransmission through 5-HT synapses with 5$\mathrm{HT}_{2 \mathrm{c}}$ receptors in untreated mild-moderate

\section{CLINICAL IMPLICATIONS}

Mild-moderate depressive illnesses are common in community settings and are mostly undetected and untreated.

- Recent life events evoke physiological stress responses, as measured by salivary cortisol concentrations.

- Common depression found in community settings is not associated with sustained increases in cortisol concentrations, but does show abnormal serotonin (5-HT) function.

\section{LIMITATIONS}

Half of the cases of depression were of mild severity.

- Prolactin responses to dexfenfluramine are a probe of $5-\mathrm{HT}_{2 \mathrm{C}}$ but not $5-\mathrm{HT}_{\mathrm{IA}}$ function - the receptor type implicated in cortisol interactions.

- More frequent cortisol sampling would have enabled greater detailed study of cortisol secretion throughout the day and, for example, examination of secretory peaks in the pathogenesis of depression.

PAUL L. STRICKLAND, MRCPsych, J. F.WILLIAM DEAKIN, FRCPsych, CAROL PERCIVAL, PhD, JOANNE DIXON, MA, RICHARD A. GATER, MRCPsych, Neuroscience and Psychiatry Unit, University of Manchester, Manchester; DAVID P. GOLDBERG, FRCPsych, Institute of Psychiatry, London

Correspondence: Dr Paul Strickland, Neuroscience and Psychiatry Unit, Stopford Building, University of Manchester, Oxford Road, Manchester MI3 9PT. Tel: 0161275 7427; fax: 01612757429 ; e-mail: P.Strickland@man.ac.uk

(First received 2 I December 2000, final revision 2 July 200I, accepted I0 October 200I)

depression in the community. In more advanced or serious depressive illness, perhaps in combination with the effects of hospital admission, responses may become attenuated, as suggested by some fenfluramine studies discussed above. Our finding is in keeping with the theory that $5-\mathrm{HT}_{2}$ systems are activated by adversity and mediate the anxiety component of depression (Deakin, 1988). Together with our previous evidence of attenuated $5-\mathrm{HT}_{1 \mathrm{~A}^{-}}$ mediated tryptophan responses, the results are compatible with the theory that depression involves an imbalance between excessive $5-\mathrm{HT}_{2 \mathrm{C}}$ and reduced $5-\mathrm{HT}_{1 \mathrm{~A}}$ functioning (Deakin, 1988; Deakin \& Graeff, 1991).

\section{Activation of 5-HT systems in response to stress}

We have shown that psychosocial stresses activate the HPA axis but that this is not the mechanism by which psychosocial stress causes depression. Depression occurs in the absence of sustained hypercortisolaemia. ubjects with depression had reduced morning cortisol, which may be related to coexistent anxiety. Central $5-\mathrm{HT}_{2}$ neurotransmission is enhanced in depression and is responsive to life events. This is compatible with the idea that this 5-HT system is concerned with central responses to adversity. Life events and depression influence peripheral amino acid metabolism. More research is needed to determine whether this affects central 5-HT function and vulnerability to depression.

\section{ACKNOWLEDGEMENTS}

This research was funded by Wellcome Trust Grant 036979/Z/92. We thank Elizabeth Barrow, Cheryl Beresford and Jane Douglas for nursing assistance with neuroendocrine testing. 


\section{REFERENCES}

American Psychiatric Association (1994) Diagnostic and Statistical Manual of Mental Disorders (4th edn) (DSM-IV). Washington, DC: APA

Bifulco, A., Brown, G.W., Moran, P., et al (1998) Predicting depression in women: the role of past and present vulnerability. Psychological Medicine, 28, 39-50.

Brown, G.W. \& Harris, T. O. (1989) Life Events and IIIness. London: The Guilford Press.

_ , Andrews, B., Bifulco, A., et al (1990) Self-esteem and depression. I. Measurement issues and prediction of onset. Social Psychiatry and Psychiatric Epidemiology, 25 200-209.

Cowen, P. J., Clifford, E. M., Walsh, A. E., et al (1996) Moderate dieting causes $5-\mathrm{HT}_{2}$ receptor supersensitivity. Psychological Medicine, 26, II55-II59.

Deakin, J. F. (1988) $5 \mathrm{HT}_{2}$ receptors, depression and anxiety. Pharmacogical Biochemistry and Behaviour, 29, 819-820

— \& Graeff, F. G. (199I) 5-HT and mechanisms of defence. Journal of Psychopharmacology, 5, 305-315.

\section{_ , Pennell, I., Upadhyaya, A. J., et al (1990) A}

neuroendocrine study of $5 \mathrm{HT}$ function in depression: evidence for biological mechanisms of endogenous and psychosocial causation. Psychopharmacology (Berlin), I0I 85-92.

Dinan, T. G. (1994) Glucocorticoids and the genesis of depressive illness. A psychobiological model. British Journal of Psychiatry, 164, 365-37I.

Dolan, R. J., Calloway, S. P., Fonagy, P., et al (1985) Life events, depression and hypothalamic-pituitaryadrenal axis function. British Journal of Psychiatry, 147, 429-433.

Franklin, M., Cowen, P. J. \& Craven, R. D. (1995) The effects of a low tryptophan diet on brain 5-HT metabolism and 5-HT mediated responses in the male rat. Journal of Psychopharmacology, 9, 336-34I.

Goodall, E. M., Cowen, P. J., Franklin, M., et al (1993) Ritanserin attenuates anorectic, endocrine and thermic responses to $d$-fenfluramine in human volunteers. Psychopharmacology (Berlin), II2, 46I-466.
Goodyer, I. M., Herbert, J., Altham, P. M., et al (1996) Adrenal secretion during major depression in 8- to 16-year-olds. I. Altered diurnal rhythms in salivary cortisol and dehydroepiandrosterone (DHEA) at presentation. Psychological Medicine, 26, 245-256.

_ , Tamplin, A., Herbert, J., et al (2000) Recent life events, cortisol, dehydroepiandrosterone and the onset of major depression in high-risk adolescents. British Journal of Psychiatry, I77, 499-504.

Harris, T. O., Borsanyi, S., Messari, S., et al (2000) Morning cortisol as a risk factor for subsequent major depressive disorder in adult women. British Journal of Psychiatry, 177, 505-510.

Kane, J.W. (1979) Use of sodium salicylate as a blocking agent for cortisol binding in radio-immunoassay for cortisol on extracted plasma. Annals of Clinical Biochemistry, 16, 209-212.

Lichtenberg, P., Shapira, B., Gillon, D., et al (1992) Hormone responses to fenfluramine and placebo challenge in endogenous depression. Psychiatry Research, 43, $137-146$

Lopez-lbor, J. J., Jr., Saiz Ruis, J. \& Iglesias, L. M. (1988) The fenfluramine challenge test in the affective spectrum: a possible marker of endogeneity and severity. Pharmacopsychiatry, 21, 9-14.

Maes, M., Jacobs, M. P., Suy, E., et al (1989) Cortisol ACTH, prolactin and beta-endorphin responses to fenfluramine administration in major-depressed patients. Neuropsychobiology, 2I, 192-196.

\section{_ , Calabrese, J. \& Meltzer, H. Y. (1994)}

The relevance of the in- versus outpatient status for studies on HPA-axis in depression: spontaneous hypercortisolism is a feature of major depressed inpatients and not of major depression per se. Progress in Neuropsychopharmacology and Biological Psychiatry, $\mathbf{1 8}$ 503-517.

Mitchell, P. \& Smythe, G. (1990) Hormonal responses to fenfluramine in depressed and control subjects. Journal of Affective Disorders, 19, 43-51.

Nemeroff, C. B. (1996) The corticotropin-releasing factor (CRF) hypothesis of depression: new findings and new directions. Molecular Psychiatry, I, 336-342.

O'Keane, V. \& Dinan, T. G. (199I) Prolactin and cortiso responses to $d$-fenfluramine in major depression: evidence for diminished responsivity of central serotonergic function. American Journal of Psychiatry 148, 1009-1015.

Park, S. B., Williamson, D. J. \& Cowen, P. J. (1996) 5-HT neuroendocrine function in major depression: prolactin and cortisol responses to $\mathrm{D}$-fenfluramine. Psychological Medicine, 26, II91-1196.

Siever, L., Murphy, D. L., Slater, S., et al (1984) Plasma prolactin changes following fenfluramine in depressed patients compared to controls: an evaluation of central serotonergic responsivity in depression. Life Sciences, 34, 1029-1039.

Simpson, N. (1984) Validation of a New Self-Rating Questionnaire to Detect Psychiatric Illness in General Practice: The Personal Health Questionnaire. MSc Thesis. Victoria: University of Manchester.

SPSS Corporation (1997) SPSS for Windows. Version 7.5 Chicago, IL: SPSS Inc.

Stokes, P. E., Stoll, P. M., Koslow, S. H., et al (1984) Pretreatment DST and hypothalamic-pituitaryadrenocortical function in depressed patients and comparison groups. A multicenter study. Archives of General Psychiatry, 4I, 257-267.

Strickland, P., Morriss, R., Wearden, A., et al (1998) A comparison of salivary cortisol in chronic fatigue syndrome, community depression and healthy controls. Journal of Affective Disorders, 47, 191-194.

Walsh, A. E., Oldman, A. D., Franklin, M., et al (1995) Dieting decreases plasma tryptophan and increases the prolacton response to $d$-fenfluramine. Journal of Affective Disorders, 33, 97.

World Health Organization (1992) Schedules for Clinical Assessment in Neuropsychiatry. Geneva: WHO.

- (1993) International Classification of Mental and Behavioural Disorders - Diagnostic Criteria for Research (IOth edn). Geneva: WHO.

Yehuda, R., Giller, E. L., Jr., Levengood, R. A., et a (1995) Hypothalamic-pituitary-adrenal functioning in post-traumatic stress disorder: expanding the concept of the stress response spectrum. In Neurobiological and Clinical Consequences of Stress: From Normal Adaptation to Post-traumatic Stress Disorder (eds M. J. Friedman, D. S. Charney \& A. Y. Deutch), pp. 35I-366. Hagerstown, MD: Lipincott-Raven. 